\title{
La glicoproteína-P una bomba de membrana que representa una barrera a la quimioterapia de los pacientes con cáncer
}

\author{
M. J. RUIZ GÓMEZ, A. SOUVIRON RODRÍGUEZ, M. MARTÍNEZ MORILLO \\ Departamento de Radiología y Medicina Física. Facultad de Medicina. \\ Universidad de Málaga
}

P-GLYCOPROTEIN, A MEMBRANE PUMP THAT REPRESENTS A BARRIER TO CHEMOTHERAPY IN CANCER PATIENTS

\begin{abstract}
RESUMEN
La resistencia oncológica a múltiples agentes antineoplásicos o MDR se considera una de las mayores causas de fallo clínico en el tratamiento quimioterápico de pacientes con cáncer. El mecanismo de resistencia consiste en una disminución en la acumulación intracelular de droga por sobreexpresión de la glicoproteína-P (Gp-P). Esta proteína actúa como una bomba extrusora de drogas, dependiente de energía. El eflujo se realiza a través de un canal que forma en la membrana plasmática, constituido por doce segmentos transmembranales. La actividad de esta bomba extrusora esta regulada por la proteína quinasa $\mathrm{C}$ y presenta homología con otros sistemas de transporte. El análisis de la presencia de Gp-P y la caracterización del fenotipo MDR en biopsias tumorales podría tener gran importancia en el abordamiento del problema clínico que representa la resistencia tumoral a la quimioterapia.
\end{abstract}

PALABRAS CLAVE: Glicoproteína-P. Multirresistencia. MDR. Oncología. Quimioterapia.

\begin{abstract}
Multidrug resistance (MDR) in oncology is considered to be the main cause of chemotherapy failure in the treatment of patients with can cer. The resistance mechanism consists in decrease intracellular drug accumulation by $P$-glycoprotein $(G p-P)$ overexpression. This protein acts as a drug-extracting pump that needs energy in the process. The efflux takes place by mean of a pore in the cell membrane that consist in twelve segments. The activity of this pump is regulated by protein kinase $C$ and shows homology with other transport systems. The analysis of the presence of Gp-P and the characterization of MDR phenotype in biopsy material could be important in the overcome of the resistance to cancer chemotherapy.
\end{abstract}

KEY WORDS: P-glycoprotein. Multidrug resistance. MDR. Oncology. Chemotherapy.

Ruiz Gómez MJ, Souviron Rodríguez A, Martínez Morillo M. La glicoproteína-P una bomba de membrana que representa una barrera a la quimioterapia de los pacientes con cáncer. An Med Interna (Madrid) 2002; 19: 477-485.

\section{INTRODUCCIÓN}

La resistencia oncológica a agentes antineoplásicos se considera una de las mayores causas de fallo clínico (1) en el tratamiento quimioterápico de pacientes afectos de cáncer (2-4). Los tumores desarrollan o adquieren resistencia durante el curso del tratamiento a pesar de haber presentado respuesta inicial al mismo $(5,6)$. Se estima que la resistencia a las drogas utilizadas contribuye a más del $90 \%$ de las muertes por cáncer $(7,8)$; por lo que es éste un problema importante que requiere ser abordado con la mayor eficacia posible (9).

¿Cómo se produce esta resistencia? ¿Cómo puede evitarse? Estas son las preguntas de interés que se plantean a la hora de abordar este problema. La tasa de mutación normal en una población celular se calcula en 1 por cada 105 - 108 células. Un tumor de $1 \mathrm{~cm}$ de diámetro posee cientos de millones de células y en caso de existir o aparecer una célula resistente, el tratamiento la seleccionaría, ocasionando posteriormente una recidiva resistente (10).

Experimentalmente se han obtenido tumores resistentes a drogas por selección in vitro de líneas celulares capaces de crecer en concentraciones crecientes de varios agentes citotóxicos $(11,12)$. La caracterización de modelos tumorales seleccionados para resistencia a colchicina, vincristina, vinblastina, taxol, actinomicina $\mathrm{D}$, daunorubicina y adriamicia han revelado fenotipo de resistencia a múltiples drogas, en la cual la resistencia al agente de selección está acompañada por resistencia cruzada a drogas citotóxicas de estructura y función no relacionada $(2,13,14)$. Este fenómeno se denomina resistencia a múltiples drogas (MDR) (15).

Trabajo aceptado: 29 de noviembre de 2001

Correspondencia: M. J. Ruiz Gómez. Departamento de Radiología y Medicina Física. Facultad de Medicina. Universidad de Málaga. Teatinos, s/n. 29701 Málaga. e-mail: mmorillo@auma.es 
Existe, por tanto, la posibilidad de que si las células tumorales expresan este fenotipo, puedan desarrollar resistencia aún con una quimioterapia de combinación (16).

\section{AGENTES ANTINEOPLÁSICOS. MECANISMOS DE ACCIÓN Y TIPOS}

Los agentes quimioterápicos actúan interfiriendo en los procesos fisiológicos de la proliferación celular. Sus principales objetivos son la síntesis de nucleótidos, de ADN, ARN y proteínas; inhibiendo las enzimas involucradas en estas rutas metabólicas. Sin embargo, otros agentes interfieren con los mecanismos de reparación del ADN, provocan roturas en la cadena o simplemente impiden el ensamblaje de los microtúbulos; ocasionando, en todo caso, la muerte celular. Los principales citostáticos se encuentran resumidos en la tabla I (17-21). Estos agentes se pueden agrupar de acuerdo con su efecto predominante sobre el ciclo celular. Así, se distinguen los fases específicos y no fase específicos; y éstos últimos a su vez se subdividen en ciclo específicos y no cicloespecíficos (Tabla II) (17).

\section{AGENTES FASE-ESPECÍFICOS}

Sólo son eficaces sobre las células que se encuentran en una determinada fase del ciclo celular. El aumento de dosis no se correlaciona con un incremento en la destrucción celular. Si el agente quimioterápico se expone durante un periodo de tiempo, más células tumorales podrán entrar en
TABLA II

CLASIFICACIÓN DE LOS AGENTES

QUIMIOTERAPÉUTICOS SEGÚN SU RELACIÓN CON EL CICLO CELULAR

\begin{tabular}{lc}
\hline Agentes quimioterapéuticos \\
\hline Fase específicos: & $\begin{array}{c}\text { Específicos de las fases } \mathrm{G}_{0}, \mathrm{G}_{1}, \mathrm{~S}, \\
\mathrm{G}_{2}, \mathrm{M}\end{array}$ \\
\hline
\end{tabular}

No fase específicos: Específicos del ciclo celular

No ciclo específicos

la fase del ciclo celular en la que el agente es activo, y por tanto podrá aumentar la destrucción celular. Ej.: L-asparraginasa (fase $G_{1}$ ), antimetabolitos (fase $S$ ) y los alcaloides de la vinca (fase $M)$.

\section{AGENTES NO FASE ESPECÍFICOS}

Son activos en cualquier fase del ciclo celular, y por tanto, suelen poseer una curva dosis-respuesta lineal; es decir, a mayor dosis administrada mayor fracción de células destruidas. Se distinguen a su vez dos tipos:

-Agentes ciclo específicos: Actúan sobre las células con capacidad de división; es decir sobre células localizadas en cualquier fase del ciclo celular: $G_{1}, G_{2}, S$ o $M$. Ej.: agentes alquilantes.

TABLA I

CITO STÁTICOS USADOS EN Q UIM IOTERAPIA DEL CÁNCER

Antimetabolitos Análogos del ácido fólico: Análogos de la pirimidina:

$M$ etotrexato

Arabinósido de citosina (Ara-C), 5-fluorouracilo (5-FU)

Análogos de las purinas:

6-mercaptopurina (6M P), 6-tioguanina (6TG), Deoxicoformicina, 2-clorodeoxiadenosina, Fludarabina

M itoxantrone, Bleomicina, Actinomicina D, M itomicina C, Gramicidina D, Puromicina, Paclitaxel

Antraciclinas: Doxorrubicina, Daunorrubicina, Adriamicina, Idarrubicina, Epirrubicina

Agentes alquilates

M ostaza Nitrogenada, M ecloretamina, Ciclofosfamida, Cisplatino, Ifosfamida, Clorambucil, M elfalán, Busulfano, Dacarbazina (DTIC)

Nitrosoureas: Bis-cloronitrosourea (BCNU), Cis-cloroetilnitrosourea (CCNU)

\begin{tabular}{ll}
\hline Alcoides vegetales & Colchicina \\
& Alcaloides de la vinca: Vincristina, Vinblastina, Vindesina \\
& Epipodofilotoxinas: $\quad$ Etopósido/VP-16, Tenopósido/VM -26
\end{tabular}

\begin{tabular}{ll}
\hline Taxanes & Taxol, Taxotere \\
\hline $\begin{array}{l}\text { Inhibidores de la } \\
\text { topoisomerasa I }\end{array}$ & Topotecán, Irinotecán \\
\hline M iscelánea & $\begin{array}{l}\text { L-asparaginasa, Hexametilmelamina, Hidroxiurea, Procarbazina, M -Amsa, Hidrea, L- } \\
\text { asparaginasa }\end{array}$ \\
\hline
\end{tabular}

M odificado de González y cols. (1992); O zols, (1992); M itsuhashi et al., (1992); M ehta et al., (1992); Rankin y Kaye, (1990). 
-Agentes no ciclo específicos: Pueden destruir células sin capacidad de división, o sea, células en fase $\mathrm{G}_{0}$. Ej.: antibióticos antitumorales.

\section{EL FENOTIPO DE RESISTENCIA A MÚLTIPLES DROGAS (MDR)}

Las dos principales manifestaciones de la resistencia a drogas son: resistencia intrínseca, la cual está relacionada con el fallo de la quimioterapia inicial y resistencia adquirida en la que inicialmente el tumor responde a la quimioterapia pero más tarde se vuelve resistente al tratamiento inicial y además a la terapia con otras drogas diferentes (22-24).

Los mecanismos de resistencia observados en células MDR son $(3,4,8,25)$ :

-Disminución en la acumulación intracelular de droga.

- Sobreexpresión de la glicoproteína-P (Gp-P).

-Inactivación metabólica de drogas, mediada por glutatión (GSH).

- Resistencia mediada por topoisomerasas. drogas.

—Reparación y/o tolerancia al daño celular inducido por

En la tabla III se exponen los mecanismos de resistencia a la quimioterapia (3); los cuales corresponden a factores

\section{TABLA III}

M ECANISM OS DE RESISTENCIA

A LA QUIMIOTERAPIA

1. Factores del hospedador:

Alteraciones cinéticas

- Disminución en absorción-activación de droga

- Aumento en excreción-degradación de droga

- Alteración en proteínas de transporte

2. Factores del tumor:

M etástasis

3. Factores celulares:

Alteraciones en la permeabilidad de la membrana plasmática

Disminución en acumulación de droga

- Disminución del influjo

- Aumento del eflujo (Gp-P)

Alteraciones en metabolismo celular

- Disminución de la activación

- Aumento de la degradación

Aumento niveles de moléculas detoxificantes

- Glutatión

- GST

- Catalasa

- M etalotioneinas

Aumento de enzimas neutralizadoras de radicales libres

- Catalasa

- Superoxidodismutasa

Reparación de DNA

Tolerancia al DNA dañado

Alteración en los objetivos celulares del hospedador, del tumor o celulares. Una vez que la droga ha alcanzado el citoplasma, se expone a diferentes mecanismos de detoxificación. Algunos de ellos siempre están presentes, mientras que otros son inducidos por la presencia de la droga. Incluso cuando el citostático ha alcanzado su último objetivo y ha provocado daño en el ADN, algunas células son resistentes a causa de la gran capacidad de reparación de ese daño (26).

También se han encontrado niveles elevados de enzimas metabolizadoras de radicales libres tales como superoxido dismutasa y catalasa, asociadas a la resistencia a drogas (4). La Gp-P asociada a multirresistencia es corrientemente el mejor aspecto farmacológico, bioquímico y genético caracterizado y representa una de las mayores barreras para el éxito de la quimioterapia del cáncer (27). Se han encontrado niveles relativamente elevados en muestras diversas de biopsias de una gran variedad de tipos tumorales (12). Las células tumorales son más eficientes que las normales en cambiar su respuesta a la quimioterapia y convertirse en resistentes. Así mismo, son más mutagénicas que las normales y sus poblaciones más heterogéneas (26).

Los progresos de la biología molecular permiten ahora un mejor conocimiento de los fenómenos de resistencia, lo que permitirá un nuevo abordamiento terapéutico en el tratamiento del cáncer (28). Por tanto, los parámetros que nos permitan predecir el curso de la enfermedad pueden ayudarnos a encontrar estrategias terapéuticas adecuadas (29).

Actualmente, sólo el desarrollo de nuevas drogas y el uso de terapia de combinación produce las mejores respuestas al tratamiento. Un incremento en la intensidad del tratamiento, dando mayores dosis en periodos de tiempo más cortos, parece ser una forma de prevenir el desarrollo de resistencia a drogas (30).

\section{DISMINUCIÓN DEL ACÚMULO INTRACELULAR DE DROGAS EN CÉLULAS MDR}

La resistencia a múltiples drogas está asociada con una reducción en la acumulación intracelular de drogas $(13,15)$, al comparar las líneas celulares MDR con sus respectivas líneas parentales sensibles. La causa puede ser una menor permeabilidad celular a la droga o que ésta sea expulsada al exterior. Además, se ha visto que la acumulación de droga está inversamente relacionada con el incremento de resistencia que se produce en una selección secuencial $(18,25,26)$.

Para explicar este fenómeno se propusieron dos mecanismos diferentes:

- Las drogas entran en la célula de forma normal, pero son eliminadas por la acción de una bomba extrusora, dependiente de energía, que opera con gran capacidad en células multirresistentes.

-Una barrera de permeabilidad dependiente de energía controla la droga que entra en las células, la cual actúa con gran eficacia en células resistentes.

Actualmente se piensa que la disminución intracelular de drogas es el resultado del aumento de actividad de una bomba extrusora dependiente de energía $(23,31,32)$, ya que utilizando inhibidores de la fosforilación oxidativa en medio deficiente en glucosa, se produce un incremento en los niveles de droga intracelulares, similar a los observados en células sensibles (26). Por otro lado, parece ser que el influjo de drogas, atribui-

O btenido de Pérez y cols. (1993), modificado. 
do a mecanismos de difusión pasiva y transporte mediado, no se ve alterado en células MDR; si bien, en líneas celulares sensibles y resistentes de hámster chino el eflujo inhibe al influjo, observándose un efecto mayor en células resistentes a múltiples drogas. Este hecho sugiere que las vías de influjo y eflujo interaccionan y no son completamente independientes. Parece ser que ambos mecanismos propuestos (bomba extrusora y barrera de permeabilidad) no son mutuamente excluyentes (33).

No todas las drogas se ven involucradas en el fenotipo MDR. Todos los regímenes quimioterápicos de primera generación usados contenían al menos dos drogas no extruídas por la Gp-P; por lo que ha habido una tendencia hacia el diseño de regímenes de quimioterapia combinada de segunda y tercera generación, que incluyen agentes que no son eliminados por esta glicoproteína (34).

\section{SOBREEXPRESIÓN DE LA GLICOPROTEÍNA-P}

El estudio de las alteraciones en la respuesta a diversos compuestos y la comparación de las membranas celulares de células sensibles y multirresistentes (MDR), han puesto de manifiesto cambios en la estructura y función de la membrana plasmática (26). El hallazgo más importante, descubierto en células de hámster chino resistentes a colchicina (15), ha sido la sobreexpresión de una glicoproteína de alto peso molecular (170 kDa) (2), denominada glicoproteína-P o glicoproteína P-170 $(3,23,26,32,35)$. Se han observado un gran número de similitudes entre moléculas de Gp-P de diferentes líneas celulares, tales como glicosilación, fosforilación,...etc. La sobreexpresión de esta proteína $(31,36)$, codificada por el gen MDR1, es la responsable de la disminución en el acúmulo intracelular de drogas antineoplásicas observado en células multirresistentes $(13,37)$. El grado de resistencia usualmente, pero no siempre, se encuentra correlacionado con los niveles de expresión de Gp-P cuando una línea celular se hace progresivamente más resistente in vitro $(15,35,38)$.

La Gp-P se conserva en tamaño y reactividad inmunológica entre especies y en todas ellas se encuentra asociada con la resistencia a múltiples drogas. Se ha observado una pequeña pero consistente diferencia en el peso molecular aparente de la Gp-P en sublíneas celulares diferentes seleccionadas frente a colchicina y daunorubicina. De esta forma, los análisis realizados a Gp-P (150-180 kDa) de varias sublíneas MDR de hámster, seleccionadas con distintas drogas, dan como resultado una heterogeneidad en el tamaño y carga; sugiriendo la existencia de una familia de moléculas relacionadas (39). Estas glicoproteínas de membrana son completamente análogas a la Gp-P. La conservación de la estructura molecular de esta glicoproteína entre especies de mamíferos y su detección a bajos niveles en líneas celulares sensibles a drogas indican que debe ser un importante componente de la membrana plasmática de estas células (33).

Se ha encontrado expresión de Gp-P a altos niveles en tejidos normales de hígado, páncreas, riñón (túbulos renales), colon, yeyuno y cortex adrenal $(8,33,40)$. Esto sugiere que podría tener un papel fisiológico en procesos de secreción. En tejidos tumorales se ha visto que la correlación entre el incremento de expresión de Gp-P y la resistencia a múltiples drogas debe ser la causa del fenotipo MDR (41).
Además de la Gp-P, se ha encontrado en células multirresistentes la sobre-expresión de otra proteína de membrana con actividad ATPasa de $190 \mathrm{kDa}$, denominada "multidrug resistance-associated protein" (MRP) $(42,43)$ que igual que la Gp$\mathrm{P}$ mantiene bajos niveles intracelulares de quimioterápicos. La expresión de la proteína MRP está asociada con altos niveles de glutatión S-transferasa (44) y en algunos tipos celulares se expresa conjuntamente con la Gp-P (45).

\section{ESTRUCTURA DE LA GLICOPROTEÍNA-P}

La Gp-P ha sido caracterizada bioquímicamente como una glicoproteína de membrana plasmática que se extiende en la bicapa lipídica, la cual actúa como una bomba de membrana que activamente exporta drogas al exterior celular (46). La porción de Gp-P expuesta en la superficie celular es reactiva con la técnica de unión de carbohidratos de superficie y es además susceptible a la digestión proteolítica. El mapeo de los epítopos con anticuerpos monoclonales ha permitido localizar el extremo C-terminal de la molécula en la parte citoplasmática de la membrana (33).

\section{ANÁLISIS DE LA SECUENCIA DE LA GLICOPROTEÍNA-P}

El análisis de la secuencia de ADNc procedente de líneas celulares de ratón, hámster y humanos, que codifican para el gen de la Gp-P ha permitido conocer la secuencia completa de aminoácidos de la molécula. La secuencia de ratón presenta 1.276 aminoácidos mientras que la humana contiene 1.280 $(2,8,13,15,39)$. Se les calcula una masa molecular de 140 y $141 \mathrm{kDa}$, respectivamente. Estos valores coinciden con el tamaño estimado de $140 \mathrm{kDa}$ para la porción polipeptídica de la Gp-P (37).

Se ha detectado en líneas celulares de macrófagos de ratón la presencia de dos moléculas precursoras de Gp-P diferentes; una de $120 \mathrm{kDa}$ y otra de $125 \mathrm{kDa}$. El precursor de $120 \mathrm{kDa}$ se convierte en una proteína madura de $130 \mathrm{kDa}$, mientras que el precursor de $125 \mathrm{kDa}$ madura en proteína entre 135-140 kDa, observándose variaciones en tamaño de una línea celular a otra. Estudios posteriores han identificado la existencia de dos moléculas de Gp-P diferentes, que se producen en líneas celulares MDR diferentes. Las diferencias funcionales de estas dos isoproteínas de Gp-P estriban en la mayor eficiencia que presenta la proteína producida a partir de la molécula precursora de $120 \mathrm{kDa}$; ya que células que expresan este precursor son casi cuatro veces más resistentes. Se ha podido comprobar que las dos isoproteínas de Gp-P encontradas en células MDR corresponden a los productos génicos de los genes mdr1a y mdr1b, los cuales son funcionalmente diferentes (39). En el hombre, la proteína precursora de $140 \mathrm{kDa}$ se convierte gradualmente en $170 \mathrm{kDa}$ en un periodo entre 2 y 4 horas (2).

En cada caso, la molécula de Gp-P consiste en dos mitades homólogas (dímero) (8,47-49), unidas entre sí. Cada mitad de la molécula presenta seis dominios hidrofóbicos transmembranales unidos $(2,13,50)$, dispuestos en tres pares y asociados con un dominio hidrofílico C-terminal que contiene la secuencia consenso de unión e hidrólisis del ATP $(2,15,37)$. La secuencia de aminoácidos contiene un extenso segmento hidrofóbico en el extremo N-terminal (Fig. 1) (49). Los segmentos transmembranales en la membrana plasmática están 
orientados de forma que el extremo C-terminal se sitúe en el lado citoplásmico de la membrana. Los tres pares de segmentos transmembranales están separados por largas cadenas de aminoácidos en la cara citoplásmica de la membrana y cortas cadenas en la superficie celular (33). Además, la molécula presenta una cadena externa de carbohidratos, situada sobre la cadena exterior de aminoácidos que une los dos primeros segmentos transmembranales, cerca del extremo $\mathrm{N}$-terminal de la molécula (Fig. 1) (51). Al menos 20 kDa de los 170-180 kDa de la proteína son debidos a los carbohidratos. Existen fuertes evidencias para asegurar que la porción exterior de carbohidratos no interviene en el transporte de drogas o reconocimiento.

El estudio de las secuencias de Gp-P muestra una estructura altamente conservada en la porción transmembranal N-terminal, la cual contiene las características de un dominio en forma de canal. Los dominios intracitoplásmicos de unión e hidrólisis del ATP forman un poro y actúan conjuntamente en el transporte activo de drogas al exterior celular (Fig. 1) $(15,26)$. Esta proteína actúa como una bomba extrusora dependiente de energía. El eflujo se realiza a través del poro directa o indirectamente, tras la unión a moléculas transportadoras que pueden ser un péptido o una proteína (4).

\section{MUTACIONES DE LA GLICOPROTEÍNA-P EN LA ESPECIFICIDAD POR EL SUSTRATO}

En estudios realizados sobre células de carcinoma humano $\mathrm{KB}$, resistentes a colchicina, se ha visto que la resistencia a la droga de selección está acompañada por una disminución de la resistencia a vinblastina, y que simultáneamente se produ-

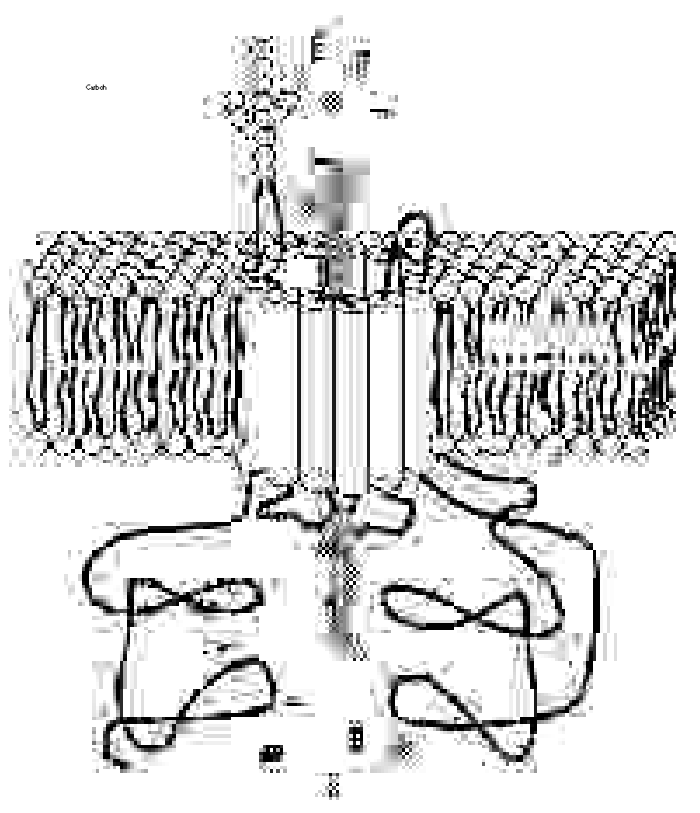

Fig. 1. Estructura tridimensional de la glicoproteína-P. Esta molécula presenta una región formada por doce subunidades ancladas en la membrana. En el centro de esta porción se sitúa un canal por donde se extruyen las drogas. Además, presenta una porción intracelular donde radica la actividad ATPasa y una cadena extracelular de carbohidratos. cen mutaciones puntuales en el gen MDR1; las cuales conducen a la sustitución de la Gly-185 por Val-185 en la secuencia de aminoácidos de la Gp-P (2,52). Esta mutación se ve amplificada al producirse la amplificación del gen MDR1, siendo la responsable de alteraciones en los patrones de resistencia cruzada. Los transfectantes que expresan esta Gp-P mutante presentan un fuerte incremento en su resistencia a colchicina y etopósido así como una disminución en su resistencia a los alcaloides de la vinca y actinomicina D $(13,53)$. El aminoácido 185 se encuentra localizado en la primera región hidrofóbica, del lado citoplásmico, de la Gp-P, y está estrechamente relacionado con las interacciones entre las drogas y la Gp-P (2). La sustitución del aminoácido en esta posición podría cambiar la especificidad de la glicoproteína en el transporte de agentes antineoplásicos, provocando una alteración en la unión con la droga o en la eliminación de la droga al exterior celular. Esta mutación altera más la eficiencia en la disociación de la droga con la Gp-P y su eliminación de la célula, que la unión inicial al citostático (13).

Sin embargo, en un estudio reciente sobre líneas KB transfectadas con ADNc se ha observado que la Gp-P mutante conduce a las células a un incremento en la resistencia al etopósido (VP16) así como a vincristina, actinomicina D y taxol. Investigaciones posteriores, realizadas con análogos de drogas fotoactivos, han mostrado que la línea celular mutante une menos colchicina y más vinblastina que la cepa silvestre. Esto sugiere que la alteración de la resistencia podría no ser debida a una asociación inicial de la droga con la Gp-P, pero sí a una disociación de ambas (2).

\section{HOMOLOGÍA DE LA GLICOPROTEÍNA-P CON OTROS SISTEMAS DE} TRANSPORTE

Existe un marcado grado de conservación en la secuencia de aminoácidos del extremo C-terminal no sólo entre moléculas de Gp-P de diferentes especies de mamíferos sino también entre la Gp-P y otras proteínas bacterianas (54), como la hlyB. Los estudios realizados sobre la importancia funcional de esta sección, altamente conservada, han mostrado la existencia de una gran homología con proteínas de transporte bacterianas que unen al ATP, tales como: his-P, malK, oppD, pstB, rbsA (37). Todas estas proteínas constituyen sistemas de transporte de sustrato de alta afinidad compuestos de una proteína periplásmica de unión al sustrato, dos proteínas de membrana hidrofóbicas y la proteína de unión al ATP (33).

La comparación de la secuencia de aminoácidos de la Gp$\mathrm{P}$ y las proteínas de transporte bacterianas muestra claramente que la porción C-terminal de cada mitad de la molécula de Gp-P contiene una unidad funcional de unión al ATP. El grado de homología entre la Gp-P de mamífero y las proteínas de transporte bacterianas es comparable al grado de homología entre las proteínas de transporte bacterianas entre sí (54). La glicoproteína-P comparte una gran homología con varios transportadores bacterianos, principalmente en la conservación del dominio de unión e hidrólisis del ATP (11), los cuales están involucrados en la incorporación de pequeñas moléculas, tales como iones, aminoácidos, péptidos y azucares (Tabla IV) $(15,37)$.

La gran homología entre cada mitad de la molécula de GpP y la proteína de membrana bacteriana HlyB (8), transportadora de alfa-hemolisina (2), sugiere que el gen de la Gp-P 


\section{TABLA IV}

PROTEÍNAS HOM Ó LOGAS U ANÁLOGAS A LA GLICOPROTEÍNA-P

\begin{tabular}{lll}
\hline Transportador & Organismo & Sustrato \\
\hline MDR1 & Humano & Drogas M DR; ? \\
MalK & E. coli & Maltosa \\
OppD,F & S. typhimurium & alfa-hemolisina \\
HlyB & E. coli & Arsenato \\
ArsA,B,C & Bacteria & Pigmentos \\
White, Brown & D. melanogaster & Factor-a \\
STE6 & S. cerevisiae & $?$ \\
pfMDR & P. falciparum & $?$ \\
CFTR & Humano & \\
Adenil-ciclasa & Bovino & AM Pc (?) \\
\hline
\end{tabular}

O benido de Biedler (1992).

pueda haberse originado por la duplicación en tandem de un gen ancestral como el HlyB (13). El extremo C-terminal de esta proteína contiene el dominio de unión al ATP, el cual es idéntico al de la Gp-P en el $50 \%$ de sus aminoácidos (2). Una de las proteínas de transporte bacterianas, RbsA, la cual comparte homología con HlyB y Gp-P en este dominio, también consiste en una molécula duplicada en tandem. El gen ancestral de Gp-P puede haber evolucionado en una familia multigénica a través de duplicaciones adicionales del gen. El análisis de la secuencia de la mitad 3' de genes de Gp-P de hámster (pgp1, 2 y 3) revela que la organización intrón-exón se conserva entre los miembros de la familia génica, indicando que ya estaba establecida antes de su desarrollo. La estructura de estos genes parece estar conservada entre especies, aunque el patrón de expresión varía entre diferentes células y tejidos (33).

Aunque se han descubierto más de 30 proteínas de unión al ATP con estructura y/o función similar a la Gp-P, sólo algunas de ellas están presentes en células eucariotas. Así, el producto del gen STE6 de Saccharomyces cerevisiae es el exportador de la feromona factor-a (MAT) (55); y el gen pfmdr1 se encuentra implicado en la resistencia a cloroquina de Plasmodium flaciparum $(2,56)$. El producto génico, CFTR, de la fibrosis cística es un miembro de la superfamilia de transportadores de proteínas procariotas y eucariotas. La adenil-ciclasa es un buen ejemplo de proteína análoga, con una pequeña secuencia idéntica a la Gp-P pero de topología considerablemente similar. Parece ser que esta proteína puede actuar exportando de la célula el AMPc sintetizado (57).

La homología encontrada entre todos estos sistemas de transporte y la Gp-P estriba en la identidad de la secuencia de aminoácidos y la similitud funcional; particularmente la relacionada con el papel de la hidrólisis del ATP para la producción de energía en los procesos de transporte de membrana (15).

\section{MODELO DE FUNCIONAMIENTO DE LA GLICOPROTEINA-P}

La información obtenida del análisis de la secuencia de aminoácidos de la Gp-P de células de ratón, humanas y hámster ha dado como resultado un modelo estructural de esta proteína de membrana (Fig. 1). La Gp-P forma un canal en la membrana plasmática y transporta drogas fuera de la célula usando la energía derivada de la hidrólisis del ATP (Fig. 2) $(11,12)$. Cada mitad de la molécula no actúa independientemente en el transporte de drogas, ya que la inactivación de uno o dos puntos de unión e hidrólisis del ATP conlleva a la pérdida de la actividad de esta proteína (15).

En una versión de este modelo las drogas se unen a la Gp$\mathrm{P}$ directamente y después son eliminadas de la célula. En este punto hay que hacer dos consideraciones:

- La unión de la droga a la Gp-P debe ser reversible ya que las moléculas de droga tienen que ser eliminadas de la superficie celular.

- La transfección de ADNc de Gp-P a células sensibles da como resultado resistencia cruzada a drogas no relacionadas estructuralmente; por lo que la molécula de Gp-P debe tener sitios de unión para un diverso grupo de drogas, probablemente en su dominio hidrofóbico.

Existe evidencia experimental para sostener esta versión, ya que se han observado en líneas celulares MDR vesículas de membrana que sobreexpresan una proteína de 150-180 kDa, la cual presenta puntos específicos de unión para vinblastina. Esta unión es inhibida por dos de las drogas con las que presentan resistencia cruzada (vincristina y daunorubicina). Este hecho sugiere que estos citostáticos pueden competir por el mismo punto de unión o unirse a sitios extremadamente adyacentes (33). La Gp-P también une a otras drogas involucradas en el fenotipo MDR, tales como colchicina y actinomicina D, las cuales no compiten por el punto de unión para vinblastina en las vesículas de membrana (15).

La reversión de la resistencia a múltiples drogas puede ocurrir por la inhibición de la unión de las drogas con la Gp-P. Existen dos evidencias que sugieren que puede haber múltiples dominios de unión a drogas en la Gp-P:

- La inhibición de la unión de análogos de la vinblastina a la Gp-P no está relacionada con la habilidad para revertir la

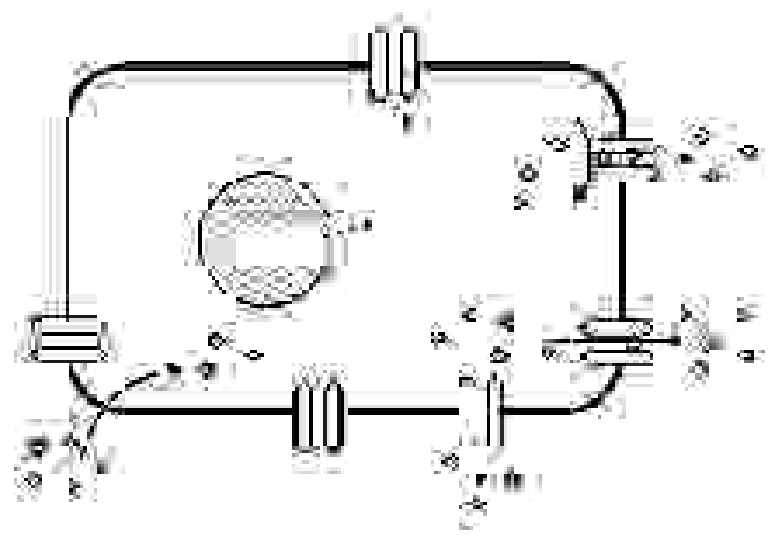

Fig. 2. Resistencia mediada por glicoproteína-P. La proteína sintetizada se coloca en la membrana plasmática. Las drogas que entran en la célula son expulsadas al exterior a través del poro que forma esta molécula. El proceso se realiza mediante la energía liberada de la hidrólisis del ATP. Las moléculas como el verapamil son capaces de inhibir este eflujo, provocando una acumulación intracelular de droga. 
resistencia a varios compuestos tales como trifluoperazina y cloroquina (33).

-Drogas como colchicina y actinomicina D, que están involucradas en el fenotipo MDR no compiten por el sitio de unión a vinblastina en las vesículas de membrana de células multirresistentes (15)

En la segunda versión del modelo de funcionamiento, una proteína de unión a la droga es transportada fuera de las células por la Gp-P, que actúa como una bomba $(8,35)$, de forma similar a la exportación de alfa-hemolisina por HlyB de E. coli $(9,13,15)$. Las drogas se unen irreversiblemente a esta proteína y el complejo droga-proteína es eliminado de la célula. Esta proteína de unión puede ser un componente celular expresado normalmente, pero debe ser producido en cantidades suficientes ya que se exporta continuamente.

La Gp-P ha sido purificada a partir de extractos de membrana y se ha observado que presenta actividad ATPasa. Esto permite determinar si la hidrólisis del ATP por la Gp-P está emparejada al eflujo de droga, tal como predice este modelo. La exagerada presencia de una molécula compleja como la Gp-P en la membrana plasmática de células MDR produce múltiples efectos sobre la estructura y función de la misma, incluyendo permeabilidad y respuesta a agentes activos de membrana tales como ionóforos, anestésicos locales y detergentes no-iónicos. La resistencia a colchicina en células MDR muestra características que indican la existencia de una barrera de permeabilidad dependiente de energía. La colchicina se une con gran afinidad a su objetivo intracelular, la tubulina, y parece ser que un mecanismo de eflujo de drogas puede competir con la tubulina por la colchicina intracelular (33).

\section{REGULACIÓN DE LA GLICOPROTEÍNA-P POR LA PROTEÍNA QUINASA C}

La proteína quinasa $\mathrm{C}(\mathrm{PKC})$ juega un papel importante en la resistencia a múltiples drogas $(58,59)$. Varias modificaciones post-translacionales de la molécula de Gp-P tales como glucosilación y fosforilación podrían ser consideradas como posibles mecanismos de modulación de su función; ya que contiene un gran componente de carbohidratos que supone aproximadamente el $20 \%$ de su masa molecular relativa y además la Gp-P puede ser fosforilada in vivo e in vitro (60). Las células mutantes MDR deficientes en glucosilación no presentan cambios en los patrones de resistencia cuando se comparan con las células parentales (2).

Parece ser razonable que las diferencias de fosforilación puedan jugar un papel importante en la alteración del fenotipo MDR. En consecuencia, se ha visto en células resistentes una alteración en las actividades enzimáticas de varias quinasas y/o fosfatasas (61). La Gp-P es fosforilada en la porción basal por la PKC, lo que afecta al transporte de drogas. Esta fosforilación se incrementa dos veces mediante el tratamiento con ésteres de forbol, en algunas líneas celulares de carcinoma. Sin embargo, la estaurosporina y el H7, inhibidores de la PKC y de la actividad de la proteína quinasa dependiente de AMPc, no afectan a la tasa de fosforilación de la Gp-P. En estudios realizados sobre células HL60 resistentes a vincristina se ha demostrado que existe otra proteína quinasa (PK1) asociada a la membrana, la cual también fosforila a la Gp-P en residuos de serina y treonina, pudiéndose regular así los niveles de resistencia a múltiples drogas $(62,63)$.
La actividad de la Gp-P puede ser regulada por los agentes quimioterapéuticos. Este modelo (Fig. 3) predice que la exposición de las células a las sustancias anfipáticas, tales como antraciclinas, activa la fosfolipasa C (PLC), la cual cataliza la conversión de fosfatidil-inositol 4,5-bifosfato (PIP2) en inositol 1,4,5-trifosfato (IP3) y 1,2-diacil-glicerol (DAG). El aumento de los niveles de DAG en la membrana da como resultado la traslocación de la PKC a la membrana plasmática, donde fosforila a la Gp-P. La fosforilación de la Gp-P aumenta la actividad extrusora y conduce a la eliminación de la droga de la membrana, con lo cual vuelve la actividad de la PLC a su estado basal. Tras el metabolismo de DAG, la Gp-P es desfosforilada gracias a la acción de fosfatasas específicas de serina/treonina, las cuales hacen que vuelva a su estado basal. La actividad de las fosfatasas podría ser incrementada mediante la liberación de calcio intracelular del retículo endoplásmico por el IP3 (31). En consonancia con esta alteración, los grupos fosfato de la Gp-P son metabólicamente activos y la proteína sufre ciclos rápidos de fosforilación y desfosforilación; lo que sugiere que este hecho juega un papel importante en la actividad biológica de esta molécula de transporte (64). Las alteraciones del estado de fosforilación de la Gp-P parecen estar involucradas en los mecanismos de acción de varios compuestos que aumentan la acumulación de droga en células MDR, resultando en una reversión de la resistencia a drogas. Así, el verapamil y la trifluoperazina, entre otras, revierten parcialmente la multirresistencia. Cambios en la fosforilación de proteínas parecen estar también involucrados en la reversión de la multirresistencia por estos compuestos (33).

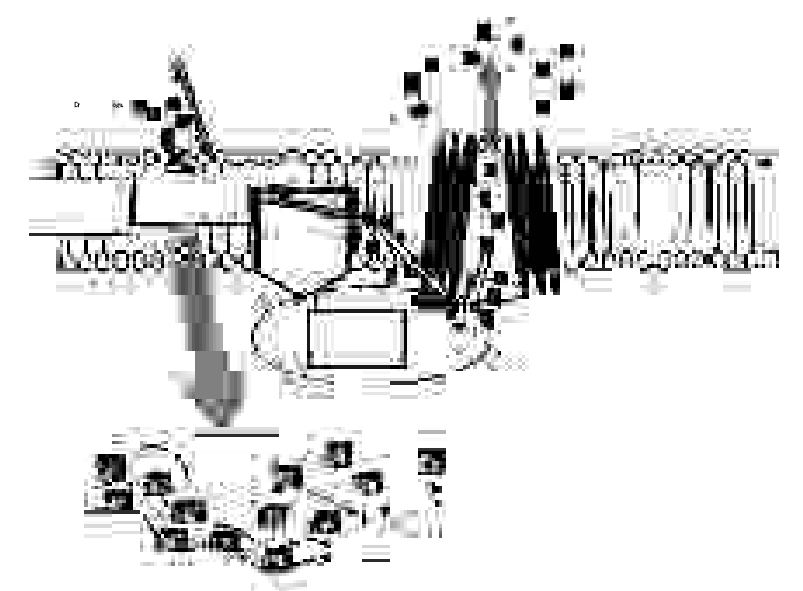

Fig. 3. Regulación de la actividad de la glicoproteína-P por la proteína quinasa $C$ (PKC). La fosfolipasa C (PLC) es activada por las drogas antitumorales para catalizar la conversión de fosfatidil-inositol 4,5-bifosfato (PIP2) en inositol 1,4,5-trifosfato (IP3) y 1,2-diacil-glicerol (DAG). La producción de DAG conduce a la translocación de la PKC a la membrana celular donde fosforila a la Gp-P aumentando su actividad. La extrusión de droga de la célula inactiva la PLC y el DAG es metabolizado. Posteriormente, la Gp-P es defosforilada por la acción de fosfatasas serina/treonina, las cuales fueron activadas por el calcio liberado del retículo endoplásmico por el IP3. 


\section{PLANTEAMIENTOS PARA EL FUTURO}

Las células cancerígenas fallan en su respuesta a la quimioterapia por muchas razones. Algunos investigadores dudan en la relevancia de los mecanismos bioquímicos de la resistencia a drogas porque factores relativos al hospedador, tales como absorción de droga, distribución, metabolismo, excreción y el fallo en el desarrollo de una dosis adecuada, no son los únicos que pueden influir en la respuesta de los tumores. Otros factores importantes a tener en cuenta son el tamaño tumoral, cinética celular, suministro vascular, inmunocompetencia, grado de oxigenación y $\mathrm{pH}$. Las células cancerígenas pueden mostrar resistencia intrínseca o adquirida a alguna droga por muchos mecanismos diferentes (26).

El desarrollo de nuevos agentes, que puedan tener diferentes mecanismos y puntos de acción será de especial interés; así como la investigación de nuevos objetivos celulares. En este sentido será importante el estudio de la especificidad de agentes contra las células malignas $(21,27)$.

\section{Bibliografía}

1. Beck WT, Qian X. Photoaffinity substrates for P-glycoprotein. Biochem Pharmacol 1992; 43: 89-93.

2. Harris AL, Hochhauser D. Mechanisms of multidrug resistance in cancer treatment. Acta Oncologica 1992; 31: 205-13.

3. Perez RP, Hamilton TC, Ozols RF, Young RC. Mechanisms and modulation of resistance to chemotherapy in ovarian cancer. Cancer 1993; 71: $1571-80$

4. Stavrovskaya AA. Cellular mechanisms of multidrug resistance of tumor cells. Biochemistry (Mosc) 2000; 65: 95-106

5. Booser DJ, Hortobagyl GN. Anthracycline antibiotics in cancer therapy. Drugs 1994; 47: 223-58

6. De Vita Jr VT. Principles of chemotherapy. In: VT De Vita Jr.S, Hellman S.A. Resenberg JB. Lippincott Co, editors. Cancer. Principles and Practice of Oncology. 3rd ed. Philadelphia, USA; 1989.

7. Young R. Mechanisms to improve chemotherapy effectiveness. Cancer 1990; 65: 815-22.

8. Lum BL, Fisher GA, Brophy NA, et al. Clinical trials of modulation of multidrug resistance, pharmacokinetic and pharmacodynamic considerations. Cancer 1993; 72: 3502-14

9. Roepe PD. What is the precise role of human MDR1 protein in chemotherapeutic drug resistance? Curr Pharm Des 2000; 6: 241-60

10. Souviron Rodríguez A, Ruiz Gómez MJ, Morales Moreno JA, Martínez Morillo M. Multirresistencia a drogas (MDR) en oncología. An Med Intern, Madrid 1997; 14: 145-53.

11. Juranka PF, Zastawny RL, Ling V. P-glycoprotein: multidrug resistance and a superfamily of membrane-associated transport proteins. Faseb J 1989; 3: 2583-92.

12. Slovak ML, Coccia M, Meltzer PS, Trent JM. Molecular analysis of two human doxorubicin-resistant cell lines: evidence for differing multidrug resistance mechanisms. Anticancer Res 1991; 11: 423-8.

13. Roninson IB. The role of the MDR1 (P-Glycoprotein) gene in multidrug resistance in vitro and in vivo. Biochem Pharmacol 1992; 43: 95-102.

14. Patel NH, Rothenberg ML. Multidrug resistance in cancer chemotherapy. Invest New Drugs 1994; 12: 1-13

15. Biedler JL. Genetic aspects of multidrug resistance. Cancer 1992; 70: 1799-809.

16. Marie JP. Los gènes de résistance à la chimiothérapie. La Presse Médicale 1992; 21: 1033-7.

17. González Fernández FA, Pérez Calvo J, Garcia Diaz C. Quimioterapia en hematología. Medicine 1992; 6: 576-86.

18. Ozols RF. Chemotherapy for advanced epithelial ovarian cancer. Hematol/Oncol Clin North Am 1992; 6: 879-93.
En un futuro habrá que poner más énfasis en los oncogenes, factores de crecimiento, mensajeros intra e intercelulares y los factores que regulan la expresión de los genes. Determinados genes y sus productos podrían ser objetivos atacados por secuencias de nucleótidos complementarias con las que hibriden y se podría conseguir así la inhibición de la expresión de secuencias específicas de ADN y ARN (4,65). De la misma forma, el modelado molecular podría resultar en la producción de estructuras químicas que se unirían estrechamente, inhibiendo moléculas específicas. Así, las drogas contra el cáncer en el futuro serán más específicas $(9,21,46)$, aunque esto no es garantía de que sean más efectivas. El ADN será reemplazado por la membrana celular como objetivo principal. Mediante la determinación de las bases moleculares de la sensibilidad a las drogas, sería posible extender el éxito de la quimioterapia a más pacientes. Por el momento, parece ser que la caracterización del fenotipo MDR en biopsias tumorales podría tener gran importancia en el abordamiento del problema clínico que representa la resistencia tumoral a la quimioterapia.
19. Mitsuhashi Y, Inaba M, Sugiyama Y, Kobayashi T. In vitro measurement of chemosensitivity of human small cell lung and gastric cancer cell lines toward cell cycle phase-nonspecific agents under the clinically equivalent area under the curve. Cancer 1992; 70: 2540-6.

20. Mehta BM, Rosa E, Fissekis JD, Bading JR, Biedler JL, Larson SM. Invivo identification of tumor multidrug resistance with tritium-3-colchicine. J Nucl Med 1992; 33: 1373-7.

21. Rankin EM, Kaye SB. Principles of chemotherapy. In: Sikora K, Halnan KE, editors. Treatment of cancer. London: Chapman and Hall Medical; 1990. p. 127-45.

22. Schimke RT. Methotrexate resistance and gene amplification, mechanisms and implications. Cancer 1986; 57: 1912-7.

23. Brian LJ, Dalton W, Fisher GA, Sikic BI. Reversal of multidrug resistance to cancer chemotherapy. Cancer (supl.) 1993; 72: 3484-8.

24. Johnstone RW, Ruefli AA, Smyth MJ. Multiple physiological functions for multidrug transporter P-glycoprotein? Trends Biochem Sci 2000; 25: 1-6

25. Johnson SW, Ozols RF, Hamilton TC. Mechanisms of drug resistance in ovarian cancer. Cancer 1993; 71: 644-9.

26. Masters JR. Biochemical basis of resistance to chemotherapy. Radiother Oncol 1990; 19: 297-305.

27. Sharma V, Beatty A, Wey SP, et al. Novel gallium(III) complexes transported by MDR1 P-glycoprotein: potential PET imaging agents for probing P-glycoprotein-mediated transport activity in vivo. Chem Biol 2000; 7: 335-43.

28. Pastan I, Gottessman MM. Multidrug resistance. Annu Rev Med 1992; 42: 277-86.

29. Mayer A, Takimoto M, Fritz E, Schellander G, Kofler K, Ludwig H The prognostic significance of proliferating cell nuclear antigen, epidermal growth factor receptor and mdr gene expression in colorectal cancer. Cancer 1993; 71: 2454-60.

30. Sevin BU, Perras JP, Averette HE, Donato DM, Peñalver M. Chemosensitivity testing in ovarian cancer. Cancer 1993, 71: 1613-20.

31. Hait WN, Aftab DT. Rational design and pre-clinical pharmacology of drugs for reversing multidrug resistance. Biochem Pharmacol 1992; 43: 103-7.

32. Tunggal JK, Melo T, Ballinger JR, Tannock IF. The influence of expression of $\mathrm{P}$-glycoprotein on the penetration of anticancer drugs through multicellular layers. Int J Cancer 2000; 86: 101-7.

33. Bradley G, Juranka PF, Ling V. Mechanism of multidrug resistance. Biochim et Biophys Acta 1988; 948: 87-128.

34. Niehans GA, Jaszcz W, Brunetto V, et al. Immunohistochemical identification of P-glycoprotein in previously untreated, diffuse large cell and immunoblastic lymphomas. Cancer Res 1992; 52: 3768-75. 
35. Sonneveld P, Durie BG, Lokhorst HM, et al. Modulation of multidrugresistant multiple myeloma by ciclosporin. The Lancet 1992; 340: 255-9.

36. Fojo AT. Multidrug resistance. Adv Intern Med 1991; 36: 195-218.

37. Gros P, Croop J, Housman D. Mammalian drug resistance gene: complete cDNA sequence indicates a strong homology to bacterial transport proteins. Cell 1986; 47: 371-80.

38. Endicott JA, Ling V. The biochemistry of P-glycoprotein-mediated multidrug resistance. Annu Rev Biochem 1989; 58: 137-71.

39. Kirschner LS, Greenberger LM, Hong Hsu SI, et al. Biochemical and genetic characterization of the multidrug resistance phenotype in murine macrophage-like J774.2 cells. Biochem Pharmacol 1992; 43: 77-87.

40. Fojo AT, Ueda K, Slamon DJ, Poplack DG, Gottesman MM, Pastan I. Expression of a multidrug-resistance gene in human tumors and tissues. Proc Natl Acad Sci USA 1987; 84: 265-9.

41. Hoffmeyer S, Burk O, Von Richter O, et al. Functional polymorphisms of the human multidrug-resistance gene: multiple sequence variations and correlation of one allele with P-glycoprotein expression and activity in vivo. Proc Natl Acad Sci USA 2000; 97: 3473-8.

42. Slapak CA, Fracasso PM, Martell RL, et al. Overexpression of the multidrug resistance-associated protein (MRP) gene in vincristine but not doxorubicin-selected multidrug resistant murine erythroleukemia cells. Cancer Res 1994; 54: 5607-13

43. Abe T, Hasegawa SW, Taniguchi K, et al. Possible involvement of multidrug-resistance-associated protein (MRP) gene expression in spontaneous drug resistance to vincristine, etoposide and adriamycin in human glyoma cells. Int J Cancer 1994; 58: 860-4.

44. Muller M, Meijer C, Zaman GJ, et al. Overexpression of the gene encoding the multidrug resistance-associated protein results in increased ATP-dependent glutathione S-conjugate transport. Proc Natl Acad Sci USA 1994; 91: 13033-7.

45. Beck J, Niethammer D, Gekeler V. High mdr1- and mrp-, but low topoisomerase II alpha-gene expression in B-cell chronic lymphocytic leukaemia. Cancer Lett 1994; 86: 135-42.

46. Ferry D, Boer R, Callaghan R, Ulrich WR. Localization of the 1,4-dihydropyridine drug acceptor of P-glycoprotein to a cytoplasmic domain using a permanently charged derivative $\mathrm{N}$-methyl dexniguldipine. Int $\mathbf{J}$ Clin Pharmacol Ther 2000; 38: 130-40.

47. Kaye SB. The multidrug resistance phenotype. Br J Cancer 1988; 58: 691-4.

48. Nuti SL, Mehdi A, Rao US. Activation of the human P-glycoprotein ATPase by trypsin. Biochemistry 2000; 39: 3424-32.

49. Booth CL, Pulaski L, Gottesman MM, Pastan I. Analysis of the properties of the N-terminal nucleotide-binding domain of human P-glycoprotein. Biochemistry 2000; 39: 5518-26.

50. Azzaria M, Schurr E, Gros P. Discrete mutations introduced in the predicted nucleotide-binding sites of the mdr1 gene abolish its ability to confer multidrug resistance. Mol Cell Biol 1989; 9: 5289-97.
51. Kast C, Canfield V, Levenson R, Gros P. Membrane topology of Pglycoprotein as determined by epitope insertion: transmembrane organization of the N-terminal domain of mdr3. Biochemistry 1995; 34: 4402-11.

52. Choi K, Chen C-J, Kriegler M, Roninson IB. An altered pattern of cross-resistance in multidrug-resistant human cells results from spontaneous mutations in the mdr1 (P-glycoprotein) gene. Cell 1988; 53: 519-29.

53. Safa AR, Stern RK, Choi K, et al. Molecular basis of preferential resistance to colchicine in multidrug-resistant human cells conferred by Gly-185 to Val-185 substitution in P-glycoprotein. Proc Natl Acad Sci USA 1990; 87: 7225-9.

54. Lewis K. Multidrug resistance pumps in bacteria: variations on a theme. Trends Biochem Sci 1994; 19: 119-23.

55. McGrath JP, Varshavsky A. The yeast STE6 gene encondes a homologue of the mammalian multidrug resistant P-glycoprotein. Nature 1989; 340: 400-4.

56. Foote SJ, Thompson JK, Cowman AF, Kemp DJ. Amplification of the multidrug resistance gene in some chloroquine-resistant isolates of $\mathrm{P}$ falciparum. Cell 1989; 57: 921-30.

57. Krupinski J, Coussen F, Bakalyar HA, et al. Adenyl cyclase amino acid sequence: possible channel-or transporter-like structure. Science 1989; 244: 1558-64

58. Blobe GC, Obeid LM, Hannun YA. Regulation of protein kinase C and role in cancer biology. Cancer Metastasis Rev 1994; 13: 411-31.

59. O'Brian CA, Ward NE, Gravitt KR, Fan D. The role of protein kinase $\mathrm{C}$ in multidrug resistance. Cancer Treat Res 1994; 73: 41-55.

60. Hamada H, Hagiwara K-J, Nakajima T, Tsuruo T. Phosphorylation of the $\mathrm{Mr} 170,000$ to 180,000 glycoprotein specific to multidrug-resistant tumor cell: effects of verapamil, trifluoperazine and phorbol esters. Cancer Res 1987; 47: 2860-5.

61. Meyers MB. Protein phosphorylation in multidrug resistant chinese hamster cells. Cancer Commun 1989; 1: 233-41.

62. Chambers TC, McAvoy EM, Jacobs JW, Eilon G. Protein kinase C phosphorylates P-glycoprotein in multidrug resistant human KB carcinoma cells. J Biol Chem 1990; 265: 7679-86.

63. Staats J, Marquardt D, Center MJ. Characterization of a membraneassociated protein kinase of multidrug-resistant HL60 cells which phosphorylates P-glycoprotein. J Biol Chem 1990; 265: 4084-90.

64. Ma L, Marquardt D, Takemoto L, Center MS. Analysis of P-glycoprotein phosphorylation in HL60 cells isolated for resistance to vincristine. J Biol Chem 1991; 266: 5593-9.

65. Cardarelli CO, Aksentijevich I, Pastan I, Gottesman MM. Differential effects of p-glycoprotein inhibitors on NIH313 cells transfected with wild-type (G185) or mutant (V185) multidrug transporters. Cancer Res 1995; 55: 1086-91. 